\title{
O alcoolismo sob a ótica dos candidatos ao vestibular da Ufes
}

\section{Alcohol abuse according to course applicants at Federal University of Espírito Santo}

Edinamara Maia, Ricardo L Martins, Márcia P César, Michela Baiôco, Rosiane G Oliveira, Paulo RM Menandro, Maria LT Garcia e Marluce S Macieira

Universidade Federal do Espírito Santo

Resumo Introdução: $\mathrm{O}$ trabalho analisou redações sobre alcoolismo de candidatos a dezessete cursos no vestibular de 1996 na Universidade Federal do Espírito Santo. O objetivo foi identificar concepções sobre causas, consequiências e propostas de intervenção em relação ao fenômeno do alcoolismo.

Métodos: Foram analisadas 2.578 redações (47,7\%). Na organização dos dados foi usado um roteiro contendo categorias de causas, consequiências e propostas de intervenção, construído a partir do exame de um conjunto de redações. Resultados: Os sujeitos mostraram concepções que enfatizam o papel da bebida alcoólica no lidar com situações de caráter negativo e o papel da pressão social como fatores causadores do alcoolismo. Entre as conseqüências do alcoolismo apareceram com destaque as familiares, as psíquicas e a dependência. Como proposta para lidar com o alcoolismo aparece com bastante destaque o conjunto de providências incluídas sob o rótulo mudanças nas políticas públicas em relação ao comércio e à propaganda de bebidas alcoólicas e também em relação à difusão de informações adequadas sobre as consequiências prejudiciais do consumo de tais substâncias.

Conclusões: As concepções são similares em todos os grupos de cursos pretendidos pelos candidatos e oscilam entre uma compreensão moral-legal e uma compreensão médico-social do fenômeno.

Descritores Alcoolismo. Concepção sobre alcoolismo. Jovens.

Abstract Introduction: The analysis of exam essays on alcohol abuse written by applicants for 17 specific undergraduate majors at Federal University of Espírito Santo (UFES) in 1996 was to identify concepts about causes, consequences and intervention proposals to alcohol abuse.

Methods: 2.578 essays (47.7\%) were analyzed. From a sample drawn from the essays, an instrument for data organization was developed by constructing categories of causes, consequences and intervention proposals.

Results: Applicants showed to believe in the relationship between alcohol and coping with personal problems and the existence of social pressure for alcohol use. Familial and psychological traumatic experience and alcohol dependence were pointed out as the main consequences of alcohol abuse. Proposals to deal with alcohol abuse such as policies for alcohol sale and advertisement of alcoholic beverages as well as mandatory warnings on the danger of alcohol consumption seemed to be the most prominent.

Conclusions: The highlighted concepts found in the all majors applicants' essays were seen in the same proportion and oscillate between a moral/legal and a social/medical understanding of alcohol abuse.

Keywords Alcohol abuse. Concepts about alcohol abuse. Young people.

\section{Introdução}

O termo alcoolismo abriga várias concepções. ${ }^{1-4}$ Cada uma dá maior relevância a um ou outro aspecto do comportamento alcoóli$\mathrm{co},{ }^{5}$ sempre em torno dos principais eixos explicativos para o alcoolismo: uma compreensão moral-legal e uma compreensão médico- social. A compreensão moral-legal circunscreve o alcoolismo à esfera do vício, ou seja, manifestação isolada de sujeito que apresentaria "desvio comportamental". A compreensão médico-social entende o alcoolismo como doença catalogada que é complexa, envolvendo aspectos culturais, comportamentais e fisiológicos..$^{6-8}$ 
Pari passu aos modelos explicativos baseados nestes eixos encontra-se outro modelo explicativo denominado compensatório, que vê o alcoolismo como comportamento aprendido, geralmente mal-adaptativo, na medida em que leva a conseqüências negativas na saúde, no estado emocional e na auto-estima. ${ }^{9}$

Dessa complexidade resultam imagens sociais confusas. $\mathrm{O}$ alcoolista é visto como fraco, sem força de vontade, sendo identificado por termos com conotações negativas, encarado como problema individual que demanda procedimentos punitivos e adoção de sanções legais. ${ }^{9} \mathrm{O}$ alcoolista é vítima de preconceitos pois é julgado a partir da convicção de que "uma vez bêbado, será sempre bêbado". ${ }^{11}$

Os meios de comunicação reforçam o comportamento de ingestão alcoólica, ficando a população, principalmente jovem, exposta a fatores que favorecem o consumo. Veiculam imagem positiva do beber, atribuindo à bebida papel facilitador das interações sociais. ${ }^{12}$

Como as propagandas de medicamentos, as de bebidas alcoólicas cumpririam duplo papel: uma função comercial e uma suposta função educativa, já que a imagem levada ao público é de uso com moderação, nunca abuso. ${ }^{13}$

Para Pinsky, ${ }^{14}$ a veiculação do produto na mídia cotidianiza, banaliza e legitima o consumo de bebidas alcoólicas, diluindo a eficácia das campanhas preventivas.

É interessante notar que a postura da sociedade frente ao consumo de álcool pode variar entre representação positiva, associada aos efeitos euforizantes da substância, e representação negativa do comportamento daquele que não consegue beber "direito".

A oportunidade de analisar textos sobre alcoolismo produzidos por jovens com elevada motivação para sair-se bem em situação de avaliação de grande impacto em suas vidas foi condição impulsionadora desta pesquisa, que objetivou identificar concepções dos vestibulandos sobre etiologia, conseqüências e propostas de intervenção relacionadas ao alcoolismo.

\section{Métodos}

No concurso vestibular de 1996, foram propostos três temas para a produção de uma redação, um deles "Alcoolismo", que foi escolhido pela maioria $(70,43 \%)$.

A instituição disponibilizou para análise vasto material produzido em condições tais (em contexto de concurso) que representam garantia de engajamento na produção textual, o que seria difícil obter em contexto tradicional de pesquisa. A prova apresentava ao candidato fragmentos de textos jornalísticos sobre alcoolismo.

Das redações sobre o tema foram analisadas $2.578,47,7 \%$ do total. Isso envolveu candidatos aos cursos de Medicina (260), Enfermagem (136), Serviço Social (182), Psicologia (178), Administração (243), Engenharia Civil (165), Agronomia (122), Biologia (179), Arquitetura (114), Matemática (133), Direito (296), Ciências Sociais (70), Comunicação (186) e Pedagogia (314).

Os cursos foram assim agrupados: a) relacionados à área de saúde (grupo I); b) conjuntos mistos de cursos relacionados às áreas de exatas e biológicas (grupos II e III); e c) relacionados à área social.
Os cursos são:

Grupo I: Medicina, Enfermagem, Serviço Social e Psicologia; Grupo II: Administração, Engenharia Civil e Agronomia; Grupo III: Biologia, Arquitetura e Matemática;

Grupo IV: Direito, Ciências Sociais, Comunicação e Pedagogia. Foi utilizado para exame das redações roteiro contendo categorias de causas (11 grupos de categorias), de conseqüências (6 grupos) e de propostas de enfrentamento do alcoolismo (5 grupos). A definição das categorias, assim como o enquadramento das respostas em tais categorias, baseou-se em análise de conteúdo. ${ }^{15}$

Para cada categoria de causas, conseqüências e propostas de enfrentamento, o resultado refere-se ao percentual total de indivíduos que mencionaram pelo menos um dos itens da categoria em consideração, tendo sido computado apenas uma vez aquele que mencionou mais de um item na mesma categoria. Foi empregado o "SPSS for Windows".

\section{Resultados}

Na concepção dos vestibulandos um ponto essencial é que o alcoolismo estaria ligado à fuga de problemas do cotidiano e à impossibilidade de resolvê-los. Beber como alternativa para lidar com situações negativas de caráter pessoal foi citado em todos os grupos, com percentuais entre $61,5 \%$ e $76,4 \%$.

Beber em decorrência de pressão social direta ou indireta foi o segundo conjunto de causas indicado (média de 68\%).

Beber como alternativa para lidar com situações negativas resultantes de aspectos sociais e econômicos e beber pelo caráter prazeroso da bebida ou da situação em que é consumida foram apontados por percentuais similares de sujeitos nos quatro grupos, variando de $30,4 \%$ a $39,0 \%$.

Diferentemente do que ocorreu para as causas, as consequiências do alcoolismo apontados pelos vestibulandos não mostraram padrão homogêneo entre os sujeitos dos diferentes grupos de cursos.

O desenvolvimento de quadro de dependência, por exemplo, foi apontado por $43,3 \%$ e $50,0 \%$ dos vestibulandos dos grupos II e IV, enquanto aqueles dos grupos I e III apontaram essa categoria em $33,0 \%$ e $38,0 \%$ das respostas.

O conjunto de consequiências psíquicas apareceu entre os três mais citados nos quatro grupos, variando entre 35,9\% (grupo IV) e 50,5\% (grupo I). Embora as causas do alcoolismo apontadas pelos vestibulandos estivessem ligadas a fatores externos que incidem sobre o indivíduo, as conseqüências individuais e coletivas foram aqui destacadas.

O conjunto de conseqüências familiares foi apontado por $52,0 \%$ dos candidatos do grupo I, como primeira opção do grupo; por 43,0\% e 40,0\% nos grupos III e IV, respectivamente, aparecendo como a segunda opção em tais grupos; e por $44,0 \%$ no grupo II, sendo a terceira opção de resposta no grupo.

Na Figura observamos que entre 55,4\% e 64,3\% dos sujeitos apontaram a necessidade de mudanças nas políticas públicas como alternativa de enfrentamento do problema. Como mudanças nas políticas públicas foram destacadas: maior controle da comercialização e das propagandas de bebidas alcoólicas.

Exceto o grupo I, os demais apontaram, como segunda escolha, 


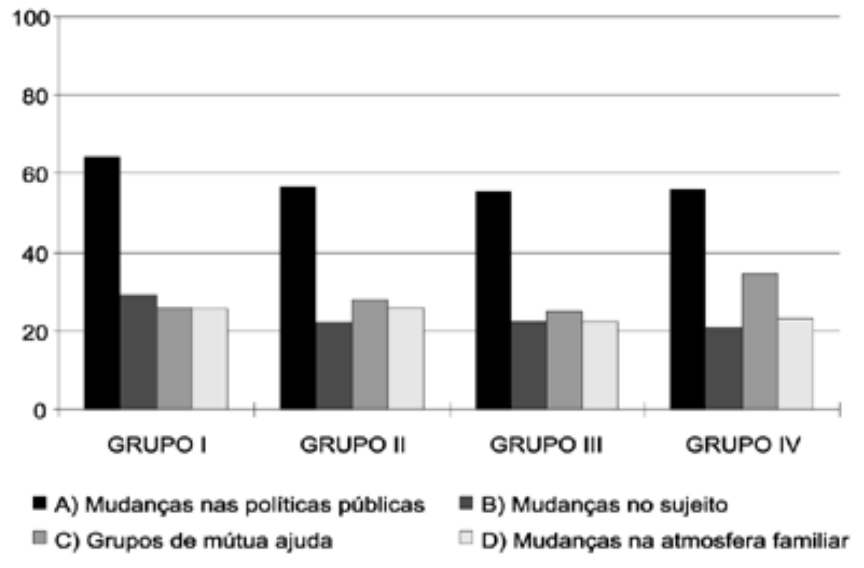

Figura - Propostas de enfrentamento do alcoolismo apontadas pelos candidatos do VEST/UFES/96 do grupo I (Medicina, Enfermagem, Serviço Social e Psicologia); do grupo II (Administraçăo, Engenharia Civil e Agronomia); do grupo III (Biologia, Matemática e Arquitetura) e do grupo IV (Direito, Comunicaçăo, Ciências Sociais e Pedagogia). Dados percentuais.

os grupos de mútua ajuda (percentuais variando entre $25 \%$ e $34,4 \%$ ).

Mudanças na atmosfera familiar apareceram como terceira opção nos grupos II, III e IV, seguidas por mudanças no sujeito.

As propostas mencionadas giram em torno de três possibilidades de intervenção: formulação de políticas públicas eficientes, mudanças nos próprios alcoolistas e acesso a atividades de suporte social.

\section{Discussão}

A problemática do alcoolismo cresce a cada dia e a adesão a alguma concepção a respeito é tomada mais pelo entusiasmo da discussão do que pelo conhecimento da ação da substância psicoativa (álcool) e suas conseqüências sobre o indivíduo e sua interação social. ${ }^{1,16}$

As imagens que os vestibulandos transportaram para as redações refletem as ambigüidades com que a informação sobre o consumo de bebidas alcoólicas circula nos meios de comunicação e na sociedade como um todo. Mesmo para indivíduos considerados como pertencentes aos segmentos sociais com mais acesso à educação formal, as dicotomias que marcam a compreensão social do alcoolismo refletiram-se na construção

\section{Referências}

1. Bertolote JM. O álcool no mundo. Conferência proferida no $1^{\circ}$ Seminário da Região Sudeste sobre Dependências Químicas; 1998 Agosto 27-29; Vitória, Espírito Santo; 1998.

2. Baiôco M. Vício ou doença: a difícil arte de não saber o que fazer com o alcoolista. [Dissertação]. Vitória: UFES; 1995.

3. Garcia MLT. Relações conjugais e conjugação de conflitos: o cotidiano de mulheres de alcoolistas [Dissertação]. Vitória: UFES; 1995.

4. Garcia MLT, Menandro PRM. A utilização de práticas surpersticiosas por mulheres de alcoolistas. Rev ABP-APAL 1997;19(2):39-44.

5. Àdes J, Lejoieux M. Comportamentos alcoólicos e seu tratamento. Lisboa: Climepsi; 1997.

6. Masur J. A questão do alcoolismo. São Paulo: Brasiliense; 1984. das concepções externadas nas redações.

Para os sujeitos o desenvolvimento do alcoolismo está associado fundamentalmente ao lidar com situações de natureza social (dificuldades nos relacionamentos e no desempenho pessoal nas situações sociais), às dificuldades decorrentes da realidade social em termos de trabalho e condição econômica, às pressões sociais de grupos de convivência e ao caráter prazeroso de muitas situações em que se consome bebida.

Permanece forte a noção de que o indivíduo bebe porque tem problemas, caracterizando-se uma estratégia de fuga de situações sociais de caráter negativo. Convivendo com tal noção aparece expressivamente a idéia de que a própria sociedade engendra situações que favorecem o consumo de bebidas, a partir das quais concretizam-se pressões dos grupos de convivência.

Isso se dá a despeito de informações objetivas sobre conseqüências negativas do consumo de bebidas alcoólicas nas diversas esferas da vida do alcoolista. É possível argumentar que permanecem claramente dissociados o alcoolismo e o consumo não abusivo, como se constituíssem realidades estanques e não parte do mesmo continuum.

Diante das ambigüidades com que o consumo de bebidas alcoólicas é encarado pela sociedade e pelos meios de comunicação, é compreensível que as propostas dos vestibulandos sobre o que fazer em relação ao alcoolismo enfatizem tanto mudanças nas políticas públicas em relação à bebida alcoólica como mudanças no próprio sujeito abusador e em sua família.

Na esfera da ação pública propõe-se a formulação de políticas de esclarecimento sobre problemas provocados pelo álcool, através de campanhas nos meios de comunicação e/ou nas escolas. Aparece também a proposta de maior controle sobre a propaganda que incentiva jovens a beberem, e a aplicação de leis rígidas que proíbam, de fato, a venda de bebidas alcoólicas a menores.

$\mathrm{Na}$ esfera da transformação do próprio alcoolista, a ênfase recai na elevação da auto-estima e do auto-controle, principalmente através dos grupos de ajuda mútua.

Se tomarmos as próprias causas reconhecidas pelos sujeitos como facilitadoras do alcoolismo, fica evidente que falta uma visão mais questionadora na base das propostas mencionadas. Tais propostas omitem a importância de transformações estruturais na organização social que proporcionem a todos padrões de vida mais estáveis e com direitos básicos atendidos.

7. Bertolote JM. Problemas sociais relacionados ao consumo de álcool. In: Ramos SP, Bertolote JM, eds. Alcoolismo Hoje. Porto Alegre: Artes Médicas; 1997. p.131-8.

8. Organização Mundial de Saúde, Coord. Classificação de transtornos mentais e de comportamento-CID-10. Descrições clínicas e diretrizes diagnósticas. Dorgival Caetano, trad. Porto Alegre: Artes Médicas; 1993.

9. Marlatt AG, Gordon JR. Prevenção à recaída: estratégias de manutenção no tratamento de comportamentos aditivos. Porto Alegre: Artes Médicas; 1993.

10. Xavier ZM, Garcia MLT, Oliveira RG. De passa-régua a pé-inchado: poder e dor no trajeto de um alcoolista. JBP 1998;47(3):125-30. 
11. Correa NR, Abilleira MG. Nossa experiência com alcoolistas [Dissertação]. INPS-SC/ Florianópolis: UFSC; 1985.

12. Masur J, Jorge MR. Dados relacionados a bebidas alcoólicas e alcoolismo no Brasil: uma revisão. Rev ABP-APAL 1986;4(8):157-65.

13. Barros JAC. Propaganda de medicamentos: atentado à saúde? São Paulo: HUCITEC; 1995.

14. Pinsky I. Análise da propaganda de bebidas alcoólicas na televisão brasileira [Dissertação]. São Paulo: USP; 1994.

15. Bardin L. Análise de conteúdo. Lisboa: Ed. 70; 1977.

16. Lima MS. Epidemiologia do alcoolismo. In: Ramos SP, Bertolote JM, eds. Alcoolismo Hoje. Porto Alegre: Artes Médicas; 1997. p. 45-64.

\section{Correspondência}

Marluce Siqueira Macieira

Universidade Federal do Espírito Santo

Programa de Pós-Graduação em Atenção à Saúde - PPGAS

Centro Biomédico

Campus Universitário de Maruípe

Av. Marechal Campos, 1468

CEP. 29040-090 Vitória, ES, Brasil

E-mail:marluce@npd.ufes.br 